\title{
SOR JUANA INÉS DE LA CRUZ Y EL BARROCO NOVOHISPANO A TRAVÉS DE LOS MODELOS NARRATIVOS DE LA FICCIÓN HISTÓRICA Y DEL BOOM HISPÁNICO FEMENINO
}

\author{
PAOLA MADRID MOCTEZUMA \\ pamoctezuma@hotmail.com
}

\section{RESUMEN}

Este artículo estudia la figura de sor Juana Inés de la Cruz y su época, a partir del análisis de la reciente novela de Mónica Lavín titulada Yo, la peor (2009), a la luz de algunos postulados de la nueva novela histórica y del llamado tardio boom hispánico femenino.

Palabras clave: sor Juana Inés de la Cruz, época colonial, narrativa mexicana actual, narrativa femenina, Mónica Lavín, Yo, la peor.

\section{ABSTRACT}

This essay deals with the figure of Sister Juana Inés de la Cruz and the period when she lived, through the recent novel written by Mónica Lavín titled Yo, la peor (2009). We also take into account the relationship between this novel and recent modes of fiction, as the New Historical Novel and feminist writing.

Key words: Sister Juana Inés de la Cruz, Colonial period, current Mexican novel, feminist writing, Mónica Lavín, Yo, la peor.

Incorporar a Sor Juana Inés de la Cruz al estudio colonial que nos ocupa, sin más, sería una muestra de ingenua osadía. Realizarlo a través del tamiz de las formas de narrar actuales es constatar, por un lado, la incesante contemporaneidad de la monja novohispana, que queda ficcionalizada por la escritora mexicana Mónica Lavín (1955) ${ }^{1}$ en una novela de muy reciente factura: $Y o$, la peor publicada en México, en el año 2009; y, por otro, que tanto la novela de corte histórico como las constantes narrativas del «boom hispánico femenino»-bautizado así por Susana Reisz hace ya un par de décadas (1990, p. 199)- se entrelazan y continúan vigentes hoy en día. Pero vayamos por partes.

1. Sor Juana «la intocable»: luces y sombras barrocas bajo una mirada oblicua

La enigmática personalidad de Sor Juana Inés de la Cruz transita desde el Barroco hasta la Posmodernidad de manera desigual, aunque persistente. Así lo refiere la escritora e investigadora Margo Glantz cuando traza su «apunte biobibliográfico» en la introduc-
Paola Madrid Moctezuma

Profesora de Lengua Española y Literatura. Ha sido becaria de investigación de la Universidad de Alicante, y actualmente finaliza su tesis doctoral sobre narradoras mexicanas contemporáneas. Ha publicado numerosos artículos sobre el citado tema, con especial dedicación a Ángeles Mastretta, Carmen Boullosa, Laura Esquivel, Elena Poniatowska y Angelina Muñiz Huberman. Ha formado parte de varios proyectos de investigación, entre ellos, el de «Relaciones literarias entre España y América Latina», dirigido por Carmen Alemany Bay, de la Universidad de Alicante.
Mónica Lavín es una narradora y periodista mexicana nacida en Ciudad de México en el año 1955. Entre sus títulos más conocidos destacan sus siguientes colecciones de cuentos: Cuentos de desencuentro y otros (1986) Nicolasa y los encajes (1991) Retazos (1995), Ruby Tuesday no ha muerto (1998), La isla blanca (1998) y Por sevillanas (2000); entre sus novelas citamos Tonada de un viejo amor (1996), Cambio de vías (1999) y Café cortado (2001); también es autora de novelas juveniles como La más faulera (1997) y Planeta azul, planeta gris (1998). En este artículo nos centraremos en su última novela, Yo, la peor (2009), publicada por la editorial Grijalbo en México.
Sor Juana Inés de La Cruz y el barroco novohispano a través de los modelos narrativos de la ficción histórica y del boom hispánico femenino

PAOLA MADRID MOCTEZUMA 




Detalle de Sor Juana Inés de la Cruz. Juan Miranda. Óleo sobre tela, siglo XVIII. Rectoría de la Universidad Nacional Autónoma de México. (Margo Glantz, Sor Juana Inés de la Cruz: Saberes y placeres, Toluca, Instituto Mexiquense de Cultura, 1996).

2

Podemos citar otros textos recientes que abordan la figura de sor Juana desde la cocina; así, en 2001 ve la luz El libro de cocina de Sor Juana Inés de la Cruz de Ángelo Morino recopilación de 36 recetas novohispanas del siglo XVII cuya transcripción pudo haber sido de la poeta mexicana; en el año 2007 aparece la novela La venganza de Sor Juana, de Héctor Zagal (1964), bajo el pseudónimo de Mónica Zagal, con la intención de demostrar, como comenta su autor en diversas entrevistas, la posibilidad por parte de un escritor de escribir novelas feministas desde el espacio privado de la cocina.

Sor Juana Inés de La Cruz y el barroco novohispano a través de los modelos narrativos de la ficción histórica y del boom hispánico femenino

PAOLA MADRID MOCTEZUMA ción al portal «Sor Juana Inés de la Cruz» de la Biblioteca Virtual Miguel de Cervantes y explica que, pese a su progresivo silenciamiento durante el siglo XVIII y las críticas en contra promovidas durante el siglo XIX por el historiador mexicano García Icazbalceta, el filólogo español Menéndez Pelayo y el crítico mexicano Francisco Pimentel, entre otros, Juana Inés de Asbaje y Ramírez de Santillana renace en los albores del siglo XX para pervivir entre nosotros hasta los de este siglo XXI. Y es que su brillante vocación cognoscitiva y escritural o su defensa del acceso de la mujer al conocimiento siguen suscitando renovado interés tanto en escritores como en investigadores o cineastas que, bajo miradas poliédricas -ya sean, entre otras, culturalistas, historicistas, feministas, cinematográficas $y$, por supuesto, literariasse han acercado a la monja novohispana con más o menos acierto.

Si bien es por todos sabido que el maridaje entre historiografía y ficción ha horadado la literatura en general, sobre todo a partir de los últimos años, en lo concerniente a México, los novelistas se han preocupado por la ficcionalización y revisión de los personajes más emblemáticos de su historia -Moctezuma, Cortés, Benito Juárez, Iturbide, el cura Hidalgo, Pancho Villa, Emiliano Zapata, etc.- y de los hitos históricos más relevantes y diversos, como son la Conquista, la Colonia, la Independencia, el Porfirismo y la Revolución o más recientes, como la matanza de Tlatelolco.

Por este motivo, la ausencia durante años de una novela centrada en un personaje de la Nueva España tan familiar y reconocido para los mexicanos como es Sor Juana Inés de la Cruz delata la diversidad y complejidad de estratos que integran el acercamiento a esta singular escritora, como son la documentación histórica de la época virreinal (palaciega, conventual, política, artística...), la lectura rigurosa de su poesía, teatro y prosa y también el amplio bagaje crítico-literario derivado de su minucioso estudio.

Sabemos, no obstante, que Dorothy Schons, investigadora norteamericana de la primera mitad del siglo XX, citada prolijamente por Octavio Paz en Sor Juana Inés de la Cruz o las trampas de la fe (1982), realizó la primera tentativa de biografiar de forma novelada $-y$ aquí radica su originalidad- a Sor Juana Inés; se trata de un trabajo inacabado e inédito, que lleva por título Sor Juana, A Chronicle of Old Mexico, a caballo entre la historia y la ficción, en cuanto a que, como explica Rosa Perelmuter (2004, pp. 137-146), se intercalan fragmentos de la Respuesta a Sor Filotea adaptados con otros textos de la poeta, así como con elementos ficcionales que permiten a la primera sorjuanista estadounidense plantear conjeturas sobre las sombras que rodean a la monja mexicana; sin embargo, no se puede considerar una novela propiamente dicha.

Es en la confluencia entre ficción histórica y narrativa femenina en la que situamos el texto de la escritora y periodista Mónica Lavín Yo, la peor, que elabora arduamente a partir de la lectura tanto de la obra de sor Juana como de los estudios críticos más señeros, incluidos en el apartado de «Bibliografía» al final de la novela. Aunque ella ya se había acercado en el año 2000 a la monja mexicana con la publicación alimón con Ana Benítez Muro del libro gastronómico Sor Juana en la cocina ${ }^{2}$, el reto de novelar sobre este personaje fue tarea difícil, como nos comenta en el anexo final que lleva por título «Escribir Yo, la peor»; aquí, la novelista arranca con el axioma «Sor Juana la intocable» para afirmar, acto seguido, que aproximarse a la escritora novohispana ha sido todo un atrevimiento. Tras esta captatio benevolentiae subyace una gran verdad: sor Juana es desbordante.

Lavín, fiel a su concepción del acto de escritura como «un intento por apresar la desafiante materia de la que están hechas las pasiones y conductas humanas", imbrica en esta novela la subjetividad, sobre todo de los personajes femeninos, con acontecimientos históricos de la segunda mitad del siglo XVII, época en la que en un pequeño pueblo mexicano llamado Nepantla nació Juana Inés, allá por el año 1648 .

Para plasmar este pasado colonial, la escritora emplea un molde ficcional histórico que no se deja seducir del todo por los ya no tan novedosos postulados de lo que críticos como Fernando Aínsa, Seymour Menton, Balderston o García Pinto han denominado «Nueva novela histórica» y que otros, como María Cristina Pons prefieren llamar «novela histórica de fines del siglo XX», «novela histórica reciente» $\mathrm{O}$ «novela histórica contemporánea».

Mónica Lavín escribe su novela a la luz de algunos procedimientos de la nueva novela histórica, como son la exhaustiva documen- 
tación de fuentes primarias y secundarias, la mezcla de elementos reales con los puramente inventados, el múltiple perspectivismo, la intertextualidad (aunque no es abundante), el abandono de personajes marmóreos, las superposiciones temporales, la variedad de modalidades discursivas y, finalmente, la subordinación del contenido histórico en pos de la valoración de aspectos más íntimos y subjetivos.

Pero la novela carece de otros elementos que definen acaso de manera más llamativa la nueva novela histórica, que son el pastiche, la parodia, los anacronismos, la carnavalización y la reinvención y revisión crítica de la historia oficial. La autora sigue de cerca, entre otros, a Octavio Paz, a Margo Glantz o a Sara Poot Herrera; no desmiente sus fuentes, sino que dialoga con ellas e implícitamente les rinde un homenaje; en este orden de cosas, por ejemplo, Lavín incide persistentemente -y éste es uno de los hilos conductores de la novela- en el descubrimiento de veinte enigmas escritos por sor Juana una vez que había vaciado su celda de libros y artilugios para dedicarse «exclusivamente» a la vida conventual. Estos textos se conocen como Los enigmas de la casa del Placer que, al parecer, estaban listos para su publicación en enero de 1695 , justo tres meses antes de que la peste acabara con la vida de sor Juana, pero que no circularon hasta 1716. Sara Poot (1999, p. 65) explica que el hallazgo de estos textos es tardío, pues en el año 1968 Enrique Martínez López los localizó en la Biblioteca Nacional de Lisboa y, 26 años después, Antonio Alatorre los editó añadiendo dos manuscritos más hallados también en dicha biblioteca.

Es claro que la publicación de los enigmas dio un giro a los estudios sorjuaninos porque se constató que sor Juana nunca abandonó su vocación de escritora. Lavín apuesta por este hallazgo con la intención de hacer de sor Juana una «heroína». Así lo expresa en el anexo del final:

Si ya el lúcido ensayo de Paz sobre sor Juana Inés había puesto el acento en su deseo de saber y en la libertad del estudio por encima de todo, el hallazgo de los enigmas (acertijos literarios que sor Juana mandaba a las monjas portuguesas para que ellas los descifraran), recalcaba la vocación irrenunciable de Juana Inés. Le devolvían su estatura guerrera, de una heroína y no de una mártir de la historia» (Lavín, 2009, p. 377).
En Yo, la peor se redimensiona para la literatura la personalidad de la escritora novohispana, pues se destaca su cara más "guerrera» y luchadora en contraposición a una posible consideración de la misma como «mártir de la historia»; pero la reposición de su vida y obra ya se había efectuado desde el campo de los estudios de crítica e investigación literaria, como acabamos de explicar. Con esto queremos destacar que la revisión de la historia oficial en el caso de la jerónima va desde la propia historiografía a la literatura y no al revés, como hubiera sido propio de la nueva novela histórica.

Muchos de los mecanismos que acabamos de mencionar coinciden, se solapan o complementan a aquéllos que son piedra angular del llamado «tardío boom hispánico femenino». Como sabemos, éste es resultado de una serie de fenómenos de índole social, antropológica, histórica y estética surgidos hacia los años setenta y ochenta que propiciaron la irrupción masiva de las mujeres a la literatura mediante una reivindicación netamente femenina. Susana Reisz de Rivarola alude al proceder de las escritoras que se sumaron a este fenómeno como «un programa estético basado en una forma muy particular de mimetismo verbal y de dialogismo sutilmente subversivo» (1990, p. 201). Qué duda cabe de que el mimetismo verbal y la subversión a los que Reisz se refiere van dirigidos a los escritores del boom hispanoamericano de los años sesenta.

La imbricación, solapamiento superposición y complementariedad de los postulados del «boom hispánico femenino» con los de la nueva novela histórica se debe a que son dos formas de alejarse de la novela totalizante; ambas beben de sus antecesores para después contravenirlos; tanto el discurso identitario y épico de la novela histórica tradicional como el de las narraciones del boom de los sesenta dan paso a una visión más subjetiva y particular de la historia, propia de la nueva novela histórica y de la narrativa femenina.

La explicación de sus concomitancias es clara, si nos atenemos a que ambos discursos narrativos son fruto de la Posmodernidad, cuyas características, descritas por Alicia Llarena a propósito de la escritura femenina, son ya un clásico para entender muchas de estas obras publicadas desde finales de los años setenta hasta nuestros días:

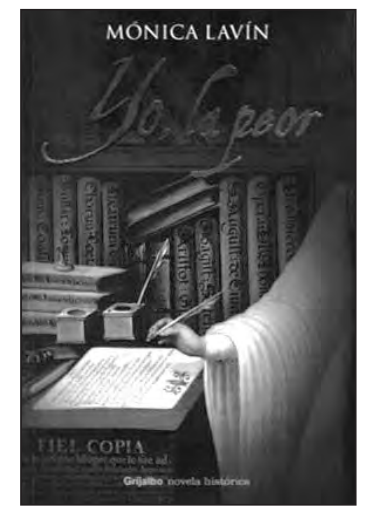

Portada de la novela Yo, la peor (2009), de Mónica Lavín.

Sor Juana Inés de La Cruz y el barroco novohispano a través de los modelos narrativos de la ficción histórica y del boom hispánico femenino

PAOLA MADRID MOCTEZUMA 


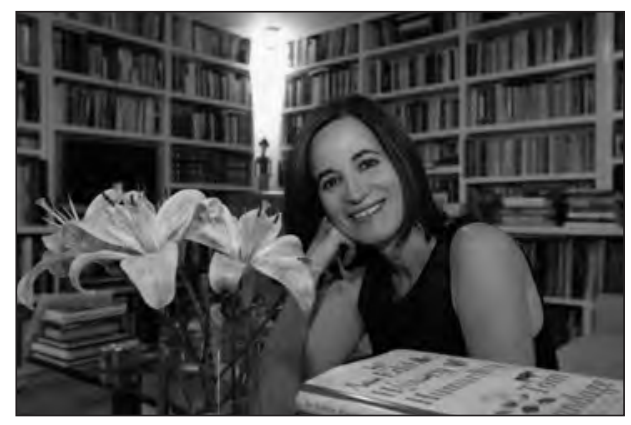

Mónica Lavín (Fotografía de Barry Domínguez).
Eclecticismo, estructuras flexibles y ligeras frente a las anteriores «narraciones totalizantes», fragmentariedad, localismo, irreverencia, pulverización de los centros y las jerarquías, trabajo sobre los márgenes, fijación en las periferias, aparición de las minorías, crítica y humor, revisión de lo cotidiano, coloquialismo y contaminación del folletín, contracultura y espontaneidad son algunos de los rasgos en los que se sostiene ese modo de ser y, por añadidura, su producción narrativa en general (1995, pp. 186-187).

La enumeración de los procedimientos narrativos anteriores coinciden, en la mayoría de los casos, con los que Biruté Ciplijauskaité establece para la narrativa femenina en primera persona de los años setenta y ochenta, a saber: la subversión en temas y en las tradiciones literarias, la inversión e ironía, la narración en primera persona, la necesidad de escribir sobre el cuerpo y las emociones, la importancia del papel atribuido al silencio, la contravención de mitos y arquetipos, la escasa importancia de la figura masculina, la polifonía narrativa y el monólogo interior, la preferencia por los espacios interiores, la incoherencia del lenguaje, la resistencia al logocentrismo, el tema de la metamorfosis, el gusto por lo inconcluso y el abordaje de temas como el erotismo y la maternidad desde distintas posturas (1988, pp. 204-225).

Sin llegar a la hipertrofia de todos estos elementos, como ocurre en la novela Malinche (2006) de Laura Esquivel, ni a la parodia, tal y como Carmen Boullosa decidió hacer efectiva en Treinta años (1999), Mónica Lavín opta por el empleo de algunos elementos de la narrativa femenina para destacar la honda preocupación de sor Juana Inés de la Cruz por afianzar su identidad en un universo barroco y colonial que estaba hecho a la medida de los hombres. Pero su uso también sirve para ambientar una época y definir al resto de personajes, tanto masculinos como femeninos. Los recursos de la nueva ficción histórica le permiten dialogar con la época novohispana y con la versatilidad de una escritora que, aunque reconocida y valorada en su tiempo, fue condenada al silencio.

A continuación, pasaremos a analizar cómo historia colonial y femineidad se dan la mano en la novela $Y o$, la peor.

\section{Estrategias posmodernas al servicio de Sor Juana y viceversa}

En el final está el principio. Me explico: en el anexo final «Escribir Yo, la peor» radica la explicación por parte de la autora del origen y construcción de la novela; su participación y diálogo con el lector se inserta asimismo en el discurso posmoderno a la vez que lo orienta para la lectura de la obra.

Lavín hace mención de la perspectiva empleada, la estructura argumental, los personajes masculinos y femeninos, los nuevos hallazgos documentales sobre sor Juana, los estudiosos con los que más dialoga su novela y lo que para ella significa la atrayente personalidad de la monja jerónima. Además, cuenta al lector que, para familiarizarse con su personaje, se propuso leer un poema a diario, aunque reconoce que la obra de sor Juana no es su materia argumental (Lavín, 2009, p. 378).

Aunque estamos de acuerdo con la autora en esta afirmación, hay una obra de la Décima Musa que se instaura como el intertexto esencial de Yo, la peor; nos referimos a la Respuesta de la poetisa a la muy ilustre sor Filotea de la Cruz (1691).

Sor Juana se reinterpreta a sí misma en la Respuesta, considerada unánimemente por la crítica como una autobiografía, no tanto de vida como de conocimiento. A diferencia de los «relatos de vida» sobre el devenir conventual, que eran encargados a las monjas de la época por parte de sus confesores y que luego ellos publicaban como modelos ejemplarizantes (Franco, 1993, pp. 29-51), en la Respuesta se justifica el afán de sor Juana por aprender a través no solo de los libros sino del universo en su conjunto.

La información que nos aporta dicho texto queda diseminada por toda la novela, imbricada siempre en la ficción novelesca; como muestra, baste citar la alusión a santa Paula en la invocación que abre la novela; la escuela Amiga a la que acude de pequeña; la anécdota del queso, consistente en que Juana Inés se privaba de él porque pensaba que la haría necia: «-No son buenos para pensar, tía» (Lavín, 2009 , p. 68), nos dice la pequeña Juana.

Más datos que se recogen de la Respuesta son la noticia de que se marcha a la ciudad de México a los ocho años; su deseo de entrar a la universidad aunque las mujeres lo tuvieran prohibido; las veinte lecciones de latín que 
recibe en casa de sus tíos de México; los castigos que ella se imponía cuando era incapaz de retener las lecciones, cortándose el pelo; la referencia al poema de raigambre gongorina Sueño y la dedicación del capítulo titulado «Trájeme a mí conmigo», situado casi al final de la novela, a la lectura que Refugio, primera maestra de sor Juana, hace de la Respuesta.

Para cimentar la importancia de este texto, la autora transcribe dos fragmentos, aquél en el que la poeta barroca justifica su elección de dedicarse a la vida religiosa y otro donde alude cómo aprendió a escribir, homenajeando de este modo a la maestra Refugio.

Pese a que en pocas ocasiones aparecen más fragmentos de textos sorjuaninos, destacan unos cuantos versos dirigidos a Lysi, la marquesa de la Laguna, con quien, como sabemos, mantuvo una profunda amistad. Los versos que se transcriben, procedentes de la composición en glosas que comienza «Cuando el Amor intentó», son recordados por la marquesa de la Laguna mientras se pone de parto: «Aunque cegué de mirarte/¿̨qué importa cegar o ver,/si gozos que son del alma/también un ciego los ve?» (Lavín, ibíd., pp. 275-276).

Aunque no como textos explícitos, las alusiones a toda su obra se hacen patentes siguiendo el orden cronológico de aparición, lo que ayuda a situar al lector en unas coordenadas temporales precisas; la mención a su producción literaria va aparejada a las anécdotas de los personajes; por ejemplo, la finalización de Los empeños de una casa coincide con el momento en el que Bernarda Linares, antigua dama de la Corte de Leonor de Carreto, consuma la venganza contra las infidelidades de su marido, ayudada por la negra Virgilia; por tal referencia, sabemos que corría el año 1683:

La negra Virgilia, que había entrado por intercesión de la madre Juana, estuvo ausente varios días. Los mismos en los que la madre Juana concluyó una obra que llamó Los empeños de una casa y la entregó a la virreina, como lo hizo saber a la priora, anunciándole que habría de presentarse en Palacio. (Lavín, ibid., p. 271).

No aparecen los años de publicación de los textos ni tampoco los de los acontecimientos históricos que traspasan la segunda mitad del siglo XVII; la autora prefiere hacerlos confluir con las historias personales y vivencias de los personajes, incluida sor Juana (de quien se nos va diciendo la edad, como una marca temporal más) y la ya comentada alusión a sus escritos; para el rastreo de fechas, ya añade Lavín un cuadro cronológico al final del libro.

No obstante, hay cuatro marcas temporales que señalan un contraste entre dos tiempos: el presente, situado el 17 de noviembre de 1694, el 17 de diciembre de 1694, el 17 de enero de 1695 y el 17 de febrero del mismo año, tras el que dos meses después, sor Juana morirá; y el pasado, que comienza cuando Juana Inés era una niña y llega a solaparse con el presente.

La aparición de las fechas se ajusta a un molde textual concreto, la carta, cuya función, además de situarnos cronológicamente, es la de desvelar las intrigas y conspiraciones de las máximas autoridades religiosas próximas a sor Juana (Aguiar y Seixas, Núñez de Miranda y Fernández de Santa Cruz); a su vez, es el vehículo idóneo para que la monja exprese sus sentimientos y resoluciones a la Marquesa de la Laguna (receptora de las mismas), además de reivindicar con ellas un modo de expresión tradicionalmente atribuido a la mujer.

La mayor parte del texto está contado por un narrador extradiegético, pero la perspectiva de todos los capítulos, excepto el titulado «La comezón», es netamente femenina, pues se presenta a sor Juana a través de la percepción que de ella y de su época tienen las numerosas mujeres de la novela.

La primera consecuencia que se deriva de este perspectivismo femenino atañe a la imagen tradicional de los personajes masculinos, que aquí son, en su mayoría, el polo opuesto al héroe de las tradicionales novelas históricas, entendiendo por tal «el personaje que logra crear para nosotros un campo ético ilusorio, que dura lo que dura la novela, y dentro de ese campo, vive una épica que nos mantendrá atrapados y deseosos de que triunfe.» (Birmajer, 2002, p. 91).

El tratamiento de estos personajes refleja los usos y costumbres de la época, con especial énfasis en aquellos que hacen de la mujer un objeto. Por ejemplo, Juan Mata, el tío de Juana Inés, aparentemente honorable marido y padre de familia, mantiene una relación adúltera con Bernarda, a quien deja embarazada para después olvidarla y seguir aleccionando a jovencitas de la Corte en las artes amatorias. Asimismo, ciertos fenómenos de carácter histórico y social quedan devaluados

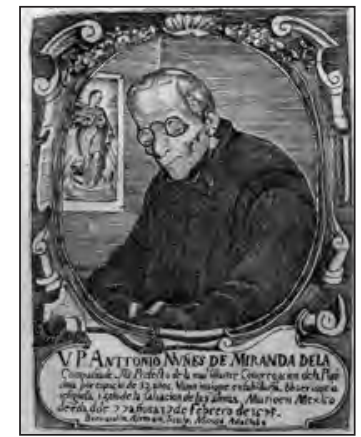

Antonio Núñez de Miranda Grabado en Vida ejemplar [...] del Padre Antonio Núñez de Miranda, de Juan de Oviedo editado en México en 1702. Fondo Reservado de la Biblioteca Nacional, UNAM. (Margo Glantz, Sor Juana Inés de la Cruz: Saberes y placeres, Toluca, Instituto Mexiquense de Cultura, 1996).

Sor Juana Inés de La Cruz y el barroco novohispano a través de los modelos narrativos de la ficción histórica y del boom hispánico femenino

PAOLA MADRID MOCTEZUMA 


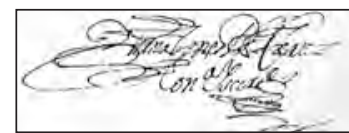

Firma de Sor Juana, 1690 (Margo Glantz, Sor Juana Inés de la Cruz: Saberes y placeres, Toluca, Instituto Mexiquense de Cultura, 1996).

3

Si bien sor Juana denominó a este texto en el que, como es sabido, contravenía el Sermón del Mandato del padre Vieyra sobre las finezas de Cristo, Crisis de un sermón, Fernández de Santa Cruz lo titula Carta Atenagórica, es decir, propio de Atenea, diosa de la sabiduría. Sin embargo, lejos de parecernos un halago, cabe la posibilidad de interpretar este "rebautismo» como un acto más de imposición patriarcal al tiempo que incide en la adyacencia de sor Juana a una genealogía cultural masculina (implícita al siglo XVII, no era necesario reafirmarla), ya que Atenea nace directamente de la cabeza del dios Zeus-padre.

Sor Juana Inés de La Cruz y el barroco novohispano a través de los modelos narrativos de la ficción histórica y del boom hispánico femenino

PAOLA MADRID MOCTEZUMA en boca de los hombres, pues, para Juan Mata, el mestizaje se entiende como un mero acto de virilidad de un español con una india (y no a la inversa) cuando éste no puede esperar a la mujer peninsular.

Por otra parte, la asociación de las atrocidades inquisitoriales con la masculinidad se hace patente en el instante en que María, tía de Juana Inés, escucha la conversación que la india Trini mantiene con su sobrina y la maestra Refugio en la cocina sobre una dominica quemada viva en la plaza del Volador y comprende que, a la mujer, sea cual sea su raza o clase, le espera la misma suerte, ya que «eran los hombres y no ellas quienes delataban, sentenciaban y ejecutaban» (Lavín, 2009, p. 116).

El tema de la Inquisición se menciona, aunque de manera ancilar, en varios momentos de la novela, asociado al peligro que corre la escritora mexicana a raíz de la publicación de su Crisis de un sermón (1690) o, como la llamó el obispo de Puebla, Carta Atenagórica; no en vano sabemos por el Catálogo de textos marginados. Inquisición: siglo XVII, publicado en 1997, que hubo un proceso inquisitorial que había involucrado el nombre de Sor Juana (Poot, 1999, p. 64); de ahí la conocida frase extraída de la Respuesta: «yo no quiero ruido con el Santo Oficio» (Sor Juana Inés de la Cruz, 1978, p. 52).

Volviendo a los personajes masculinos, observamos que otros, más bien desdibujados, sirven o bien para contrastar su insignificancia con la brillantez de Juana Inés, como ocurre con su pretendiente, Cristóbal Pocillo, o bien para mostrar su ineptitud al mando de toda una Colonia, como es el caso de Tomás de la Cerda, marqués de la Laguna, que es incapaz de controlar los saqueos de los piratas en el puerto de Veracruz. Los hombres son también sinónimo de ausencia, como el padre de Juana Inés, Pedro de Asbaje y, más adelante, su padrastro Diego Ruiz Lozano.

No cabe duda de que la autora arremete con más virulencia sobre la tríada de lo que ella denomina «los lobos»: el arzobispo de México Aguiar y Seixas, el confesor de sor Juana Antonio Núñez de Miranda y el obispo de Puebla Manuel Fernández de Santa Cruz.

En los cuatro capítulos titulados «Los lobos», correspondientes a las cartas que sor Juana envía a María Luisa, ajustándose a la historia real de los hechos, Lavín presenta a
Aguiar y Seixas, «el lobo mayor», como un misógino enemigo del teatro y de las mujeres; a Núñez de Miranda se le describe como un hombre sucio, de "cuerpo hediondo", con «ropas raídas» capaz de amedrentar en el confesionario a Bernarda, a sor Cecilia o a Isabel María con su severidad y mal olor; es Núñez de Miranda el que supervisa que sor Juana desmantele su celda y se deshaga de libros e instrumentos científicos y musicales.

De igual modo, se alude a un tercer lobo, el que sor Juana considera más peligroso por haber sido su amigo hasta la publicación de La carta Atenagórica ${ }^{3}$ y La carta de Sor Filotea de la Cruz; la traición de Fernández de Santa Cruz se resignifica como doble, pues su «travestismo» al firmar como una monja - mascarada femenina- contraviene no solo a sor Juana sino al género femenino en su conjunto; en el capítulo "La comezón», casi al final de la novela, nos encontramos con un personaje completamente desmitificado que, lejos de arrepentirse por el daño causado a la monja, se rasca imperiosamente los testículos mientras recuerda sus escarceos de travestismo juvenil. Parece que, tras esta crítica al género masculino, Mónica Lavín hace renacer las famosas redondillas «Hombres necios» de la Fénix de América.

Pese a lo hasta aquí descrito, hay dos personajes masculinos a los que la autora confiere dignidad: el abuelo Pedro y Hermilo Cabrera; al primero le redime su afán por la cultura -es quien permite el acceso de la niña Juana Inés a su biblioteca- y al segundo, una vida llena de sufrimiento por su condición de mulato.

Por otra parte, estamos de acuerdo al afirmar que la búsqueda de afinidades entre personajes femeninos ha sido, a menudo, medular en el proyecto de la escritura femenina. Se trata de lo que el nuevo feminismo francés denominó «genealogía femenina», referida a las relaciones simbólicas entre mujeres que traspasa los lazos de consanguinidad. Sonia Mattalía inserta esta búsqueda de genealogías y rastreo del origen por parte de las escritoras dentro de una manifestación de lo que ella denomina «la experiencia de la revuelta» (2003, p. 26).

La novela $Y o$, la peor es un proyecto genealógico, como gran parte de las novelas de narradoras mexicanas de los últimos años. En ella convergen personajes femeninos que rodean a sor Juana y nos prestan su mirada para contemplarla. 
Al comienzo, la novela se abre con una invocación a santa Paula, «patrona de las viudas», primer eslabón de la genealogía a la que sor Juana se adscribe (Lavín 2009, p. 8). En la Respuesta a sor Filotea, las mujeres con las que sor Juana deliberadamente se identifica en una suerte de genealogía simbólica son filósofas, santas, diosas, reinas, gentiles, mártires y nobles; la intencionalidad de la escritora novohispana al confraternizar con estas mujeres devela un ímpetu por estar a su misma altura, pues todas ellas fueron mujeres valientes, doctas, sabias, inteligentes y relacionadas de uno u otro modo con el estudio y la reflexión gnoseológica.

Sin embargo, mientras que en la Respuesta a sor Filotea se prima de santa Paula el que sea «docta en las lenguas hebrea, griega y latina y aptísima para interpretar las Escrituras» (Sor Juana Inés de la Cruz, 1978, p. 73), en la invocación de la que parte la novela se prepondera que sea "patrona de las viudas» alejada de «los ruidos del mundo, la música y la comida, el vino, los ropajes» (Lavín, 2009, p. 7) para así consagrarse al fervor religioso y al estudio, como lo hará la propia sor Juana. Con el fin de reforzar esta idea, cabe indicar que en época colonial, la mujer viuda tenía una posición de privilegio con respecto a otras mujeres, más aún si heredaban derechos de sus maridos; podían además disfrutar de una gran libertad y, por ello, muchas mujeres fingían estado de viudez (Tuñón, 1987, p. 51).

La cadena genealógica se completa con un vasto número de personajes femeninos que rodean a sor Juana y que, en su mayoría, forman con ella lazos de verdadero amor y respeto. En el hogar materno, Isabel, madre de Juana Inés, mujer pasional e inteligente pese a no saber leer ni escribir, posee un innato don para el gobierno de la finca en la que viven; la abuela Beatriz, por su parte, se debate entre el amor incondicional a su marido don Pedro y su amor nostálgico por España y el mar; en este personaje se articula uno de los discursos de aceptación del otro que tienen cabida a lo largo de la novela, cuando, anecdóticamente observa junto a la niña Juana Inés un mapa en el que ve lo cerca que está África de España y la sensación de «arrancamiento» que le unía a los esclavos.

Continuando con la nómina, mencionaremos a las hermanas de Juana Inés, Josefa y María quienes, pese a alejarse de sus intereses intelectuales, se presentan en sintonía con ella; la primera, en la época en que asistían juntas a la escuela Amiga y la segunda, tras su mutuo bautizo simbólico: «Princesa de estos lares», llama María a la pequeña Juana, mientras que ésta última, con más sabiduría, la nombra «María Izta de los Volcanes», sintetizando con este nombre las dos lenguas de la Nueva España, el náhuatl y el español.

Sucesora de su madre María es Isabel María, que acompañará a su tía desde el convento en los momentos más difíciles, cuando la monja ha de abjurar de los libros y, por ende, del conocimiento.

Tenemos noticia de que hubo un grupo de mujeres nobles que intervinieron en la vida de la escritora colonial y que, como ella, mostraron interés por la cultura y las letras; a algunas dedicó parte de su obra y a otras las menciona en la Respuesta. No todas aparecen referenciadas en la ficción, pero cobran en ella un papel esencial Leonor de Carreto y María Luisa Manrique de Lara. La finalidad última de que aparezcan persistentemente en la novela es la de dar una dimensión de sor Juana más mundana y humana, moviéndose en los ambientes de la Corte, pues no hay que olvidar que Leonor de Carreto la invita a vivir en Palacio y la hace su «muy favorita» ni que establece una relación profunda con la marquesa de la Laguna, con la que mantiene correspondencia y a la que dedica numerosos poemas renombrándola como Lysi o Laura.

Para concluir con el muestrario de mujeres afines a sor Juana, es necesario detenerse en aquélla que la acompaña en todas las etapas de su vida, la ya aludida maestra de la Amiga que, aunque apenas se la menciona en la Respuesta, queda rescatada desde la novelización.

Cuando en la Respuesta a sor Filotea la escritora novohispana relata cómo aprendió a leer y otros rudimentos del saber, aparece de soslayo una mujer que, sorprendida de que una niña tan pequeña tuviera ese afán por el conocimiento, comprobó satisfecha que su labor docente había fructificado:

no había cumplido los tres años de mi edad cuando enviando mi madre a una hermana mía, mayor que yo, a que se enseñase a leer en una de las que llaman Amigas, me llevó a mí tras ella el cariño y la travesura; y viendo que la daban lección, me encendí yo de manera en el deseo de saber leer, que engañando, a mi parecer, a la maestra, la dije que mi madre ordenaba me diese lección. Ella no lo creyó, porque no era créble; pero, por complacer al donaire, me la dio.
Sor Juana Inés de La Cruz y el barroco novohispano a través de los modelos narrativos de la ficción histórica y del boom hispánico femenino

PAOLA MADRID MOCTEZUMA 
Proseguí yo en ir y ella prosiguió en enseñarme, ya no de burlas, porque la desengañó la experiencia; y supe leer en tan breve tiempo, que ya sabía cuando lo supo mi madre, a quien la maestra lo ocultó por darle el gusto por entero y recibir el galardón por junto; y yo lo callé, creyendo que me azotarían por haberlo hecho sin orden. (Sor Juana Inés de la Cruz, 1978, p. 74).

Lavín bautiza a la primera maestra de Juana Inés con el nombre de Refugio Salazar, de quien nos dice: «me encontré con una cómplice perfecta, una mujer que pudiera cruzar e hilvanar todas las etapas de la vida de sor Juana, desde el descubrimiento primero de la palabra hasta sus últimos meses de despojos y ataques» (Lavín, 2009, p. 374). Es, además, la perfecta fusión del ansia por saber y las ganas de sentir, tan revalorizada por las narradoras de los últimos años; a mi juicio, es el personaje de esta novela que más entronca con el proyecto de la narrativa femenina pues su autoconocimiento proviene del propio cuerpo, del placer y del afán por aprender y enseñar; ella es quien más incita a Juana Inés para que continúe estudiando y la que más se aflige al pensar que le han cercenado la voz.

Se trata de un personaje de gran (pos)modernidad, por su complejidad y eclecticismo: maestra, feminista germinal, nostálgica empedernida; en ella, al igual que en doña Beatriz, se condensa el discurso antiesclavista de la novela; no en vano se amanceba con Hermilo Cabrera, el mulato. Varios capítulos se dedican a ella y su perspectiva es clave para conocer a la sor Juana de ficción.

Pero desde la rivalidad también se traban relaciones entre los personajes femeninos, como viene siendo habitual en muchas novelas de escritoras recientes; a las relaciones de afinidad entre mujeres les seguirán otras marcadas por antagonismos de muy diversa índole; históricamente, sabemos que sor Juana fue envidiada por su belleza e inteligencia; así lo insinúa en algunos momentos de $\mathrm{La}$ Respuesta, al reproducir la sentencia de Maquiavelo que reza del siguiente modo: «que es aborrecer al que se señala porque desluce a otros» (Sor Juana Inés de la Cruz, 1978, p. 63). Continúa con este tema más adelante, en esta ocasión, describiendo la envidia que sufrió Cristo al que, no sólo humillaron antes de crucificarlo, sino que lastimaron su cabeza con una corona de espinas para dañar su fuente de conocimiento: «la sagrada cabeza de
Cristo y aquel divino cerebro eran depósito de la sabiduría, y cerebro sabio en el mundo, no basta que esté escarnecido, ha de estar también lastimado y maltratado» (Sor Juana Inés de la Cruz, ibíd., p. 66).

En el famoso villancico dedicado a Santa Catharina de Alejandría (quien fue examinada por cincuenta doctores, del mismo modo que ocurrió a sor Juana), escrito el mismo año que la Respuesta a sor Filotea se alude, nuevamente, al sentimiento de envidia que las virtudes ajenas despiertan: "Contra una tierna Rosa / mil cierzos conjuran: / ¡oh qué envidiada vive / con ser breve la edad de la hermosura! / Porque es bella la envidian, / porque es docta la emulan: / ¡oh qué antiguo en el mundo / el regular los méritos por culpas!» (Sor Juana Inés de la Cruz, ibíd., p. 247).

En Yo, la peor, dos personajes, Bernarda Linares y sor Cecilia, representan los dos mundos por los que sor Juana ha transitado, esto es, la Corte y el convento; la primera envidia a la joven Juana Inés por ser la favorita de la virreina Leonor de Carreto; la segunda porque tiene veleidades literarias - piensa sacar a la luz una obra de teatro con el nombre sintomático de Intriga del convento- y se siente ensombrecida por la madre Juana. Aunque en ciertos momentos la envidia se trueca por solidaridad, prevalecen las calumnias, las rencillas y las mentiras que, por ejemplo, orillan a sor Cecilia a confesarse de indiscreción en vez de envidia.

Dada su personalidad janiforme, Antonio Fernández de Santa Cruz participa de esta genealogía pervertida, pues, al decir de sor Juana, a este hombre «le atenaza la envidia» (Lavín, 2009, p. 15). Ni qué decir tiene que la tía María entronca más con estas mujeres que con las de su familia, pues se niega a sí misma el derecho a disfrutar, vive amargada por las infidelidades de su marido y llama a Juana Inés «arrimada», tal y como interpreta Octavio Paz que así fue en Sor Juana y Las trampas de la fe (aunque otros críticos, como Georgina Sabat de Rivers (1997, p. 173), pongan en duda la veracidad de esta suposición).

En Yo, la peor aparecen otras sagas de mujeres marginales, las negras e indígenas, por un lado, y las mujeres de Belén, por otro.

Sobre las primeras destacamos que están relacionadas con el mundo mágico, la brujería y también con la recuperación del pasado ancestral. La negra Virgilia ayuda a Bernarda llevándola a una curandera para que aborte 
y que se cure el «mal de amores» mediante bebedizos mágicos; la negra Catalina invoca a sus ancestros por medio de cantos, junto a los demás esclavos negros, cuando el volcán entra en erupción, aliviando a indios y criollos con «aquel himno de la tierra, [...], aquel canto venido de África» (Lavín, 2009, p. 105). María de San José, esclava en el convento, descubre su felicidad a través del erotismo y la maternidad, como veremos; por su parte, la india Trini rescata el mundo prehispánico con sus historias sobre los sacrificios humanos aztecas para asustar a la hija de los Mata.

En cualquier caso, la aparición de estos personajes junto a los masculinos como Hermilo, el negro Martín o el preso que apaga el fuego del Palacio tras el motín por la falta de maíz se explica a partir de tres cauces: desde la novela histórica contemporánea, porque surge la necesidad de dar voz a las minorías para relatar la historia según la perspectiva de los vencidos; a partir de la narrativa femenina, que identifica la situación de la mujer con la de estos personajes marginados; y de acuerdo con la propia vida y obra de sor Juana, quien introduce en algunos villancicos vocablos de lenguas procedentes de África que los esclavos legaron a América. El personaje de ficción así lo justifica en la primera carta que envía a María Luisa:

Tú sabes ya que mi nombre ha sido llevado al Santo Oficio anteriormente por considerar profanos mis villancicos, porque juzgan pecaminoso que incluya a los negros y sus bailes y sus rebumbes y cadencias en el estribillo final y festivo de los villancicos que se escenifican en los atrios» (Lavín, ibid., p. 14).

Las mujeres de Belén, por su parte, constituyen un grupo apartado de la sociedad, son las parias de un mundo patriarcal que decide marginarlas ya sea por algún crimen, por prostitución, por ser consideradas «locas»e, incluso por ser adúlteras o no tener a dónde ir, como ocurre a las esclavas que adquieren su libertad.

En el capítulo que lleva por título precisamente «Las mujeres de Belén» se describen las condiciones infrahumanas en las que viven cientos de mujeres olvidadas, encarnadas en Dolores Isáureri, la madre de sor Cecilia que acusada de adulterio, fue trasladada al «Hospicio de la Misericordia». La «casa de acogida», como se llama en la época, es el resultado del peso de la institución patriarcal y religiosa, representada por Aguiar y Seixas, que castiga a la mujer con el encierro; por eso, sor Juana, aunque está más cerca de las monjas portuguesas y de las nobles de la época, se identifica en un momento dado con estas prostitutas, adúlteras, locas, tullidas, despeinadas, ruidosas, puesto que, como ella, son «mujeres sin esperanza» (Lavín, ibíd., p. 80).

La alusión a la saga genealógica cierra elocuentemente la novela, como un modo de intensificar la gran importancia que guardan las mujeres en ella; aunque la cita es extensa, la reproduzco:

Yo, la peor de todas se grabó con la sangre de la monja en aquella arcada de piedra sin que Refugio Salazar, su maestra primera, ni Bernarda Linares, lisiada de amores, ni Leonor Carreto, tan atenta a sus virtudes, ni Beatriz Ramírez, amante de don Pedro, ni María, su hermana ausente, ni su tía María, que le dio cuarto y casa en la ciudad de México, ni Catalina la negra, protectora, ni Virgilia y sus hierbas, ni Juana de San José y sus amoríos, ni Isabel María, su sobrina agradecida, ni María Luisa Manrique, su leal amiga, ni Elvira de Galve, sabedora de sus virtudes, ni santa Paula, viuda romana seguidora de san Jerónimo, ni la priora Encarnación, ni sor Filotea, que la condenó a la hoguera personal, conocieran los motivos de aquella representación.» (Lavín, ibíd., p. 370).

Como anunciamos al comienzo, una de las preocupaciones sobre las que más incide la narrativa del «boom hispánico femenino» es en encontrar un lenguaje alternativo a la lógica patriarcal a partir del cual la mujer pueda expresarse con mayor fluidez y libertad. Se trata, en todos los casos, de «un conglomerado de lenguajes que entablan un permanente diálogo entre sí, por cuanto representan visiones del mundo y sistemas de valores o ideologías» (Reisz, 1990, p. 206). Entendemos aquí por «lenguaje» los mecanismos o temas a partir de los cuales se concreta el discurso disidente de la mujer. Los que han sido más tratados por la narrativa femenina y que también rastreamos en esta novela-siempre relacionados con la vida real de sor Juana- son los siguientes:

\section{a) Resemantización de espacios y labores tra- dicionalmente atribuidos a la mujer}

Si bien la relación de sor Juana con el universo gastronómico es fehaciente, como así lo muestran pinturas de la época y referencias
Sor Juana Inés de La Cruz y el barroco novohispano a través de los modelos narrativos de la ficción histórica y del boom hispánico femenino

PAOLA MADRID MOCTEZUMA 
diseminadas en su obra (Perelmuter, 2004, pp. 43-70), no nos consta que disfrutara con ello (Lavín apud Perelmuter, ibíd., p. 45). Más bien, de acuerdo con Perelmuter y Lavín, la cocina y la gastronomía es para la monja una forma más de acceder al conocimiento. Esta visión universalista le hizo proclamar en la tan citada Respuesta aquello de "si Aristóteles hubiera guisado, mucho más hubiera escrito", frase que ha sido recuperada en múltiples ocasiones por el discurso feminista actual.

Dado que tradicionalmente la cocina ha sido un espacio represivo para la autorrealización femenina (recordemos la famosa «Lección de cocina» de Rosario Castellanos), muchas narradoras han hecho de este lugar un refugio para sus personajes femeninos y la comida adquiere poderes curativos y, en ocasiones, mágicos. En Yo, la peor la cocina es el lugar donde las mujeres se refugian y las diferencias de clase quedan canceladas: así, Juana niña, dialoga y aprende de la negra María, que pela patatas mientras la pequeña observa los conejos muertos aún calientes o los caracoles que hierven en una olla, en ese afán suyo por aprender; también desde la cocina, Josefa escribe la carta a Juana Inés, contándole que el volcán Iztaccíhuatl había entrado en erupción.

A su vez, podemos espigar varias referencias a la comida novohispana, resemantizada por el efecto que causa en los comensales; la maestra Refugio, toma bebidas calientes como el chocolate o atole para alimentar su soledad; cuando se le describe como una mujer de profunda melancolía, se le vincula al frijol negro con epazote, que fue su alimento favorito durante su infancia y juventud; por otro lado, el pan es para doña Beatriz una manera de recordar la patria perdida y añorada.

El convento se convierte en un lugar óptimo para articular el discurso gastronómico, en clara concomitancia con la realidad; se alude a numerosos los dulces y platillos elaborados por las monjas, pero vemos que a la sor Juana de ficción no le interesa cocinar, más bien escribir con primor el recetario de cocina para el convento; de hecho, le cuenta a María Luisa en la primera carta, que conecta con el final narrativo, lo alejada que se siente de las labores culinarias tras haber vaciado su celda: «Te confieso, María Luisa, que he bajado de peso, que la comida me ha dejado de interesar y que ya no meto mano en la cocina». (Lavín, 2009, p. 15). El alimento del intelecto y el del cuerpo quedan aquí identificados.
Paralelamente, se despliega un discurso de perversión culinaria en el personaje de sor $\mathrm{Ce}$ cilia, cuyo cuerpo regordete delata su segundo mayor pecado tras la envidia: la gula.

\section{b) Relación de la mujer con procesos exclusi- vamente femeninos}

En íntima relación con la adscripción de los personajes femeninos a una estirpe genealógica está el tema de la maternidad. En la narrativa femenina desde los años setenta este tema se ha afrontado desde dos posturas, ya sea considerando la maternidad como destructora del crecimiento individual de la mujer o como continuidad de un poder vivificador y mítico, alejadas ambas posiciones de lo que Adrienne Rich denomina «la maternidad como institución» (1996), es decir, aquélla que, regulada por la tradición, la religión, el falso sentimentalismo o las costumbres impuestas merma las posibilidades de autorrealización de la mujer.

En la novela se manifiestan las dos posturas anteriormente citadas; por un lado, las posibilidades de maternidad se viven como un proceso traumático en el personaje de Bernarda que, como ya es sabido, aborta con la ayuda de la negra Virgilia. Para ella, la sola idea de tener un hijo supone la imposibilidad de casarse dignamente con algún criollo o noble de la época, destino al que toda mujer tradicional estaba abocada; el otro camino, como expresa sor Juana en la Respuesta, era el convento, al que ella misma accedió para proseguir con sus estudios.

En relación a esta línea interpretativa aparecen los temas de la matrofobia y el matricidio encarnados en sor Cecilia. Ella es quien descubre a su madre cometiendo adulterio con el hermano de Pedro Velázquez de la Cadena, su padre. Para silenciarla, Dolores decide encerrarla en el convento, sin embargo, tras sucesivas confesiones de Cecilia, el cura desvela mediante anónimos la infidelidad de la mujer. Así queda justificado que, aunque la madre no lo supiese, Cecilia, al confesarse «una y otra vez tendría que repetir que odiaba a su madre y que soñaba con matarla» (Lavín, 2009, p. 220). Al resultado del matricidio simbólico le sucede algo peor: la imposibilidad de subsanar los lazos genealógicos, ya que, en un acto de heroísmo, la monja va a Belén a rescatar a Dolores pero ésta no acepta el perdón. 
Otra forma de entender la maternidad es como un proceso vivificador, en el que desde el momento del embarazo la mujer lo siente con intensidad plena. Juana de San José, la esclava negra que atiende a sor Juana en el convento, es quien representa esta interpretación; vemos cómo se ilusiona con el embarazo, lleva a su hija consigo a todas partes, siente celos de que sor Juana prodigue todas las atenciones al nuevo hijo de la marquesa de la Laguna y la incluye en el dibujo que deja a la madre Juana como de despedida porque, obviamente, no sabe escribir.

Al tema de la maternidad, le sucede el de la esterilidad o la ausencia de ser madre; aunque no queda claro en la novela si la maestra Refugio es estéril, en varios momentos se expresa su deseo fallido de tener un hijo:

Si hubiera tenido un hijo -pensaba mientras se restregaba el vientre que nunca había crecido como el de otras mujeres- le habría leído los versos de los libros, los rezos, los salmos, para que su alma se llenara del poder de las palabras (Lavín, ibid., p. 63).

Asimismo, reconoce sus esperanzas de ser madre junto a Hermilo Cabrera, concibiendo el fruto de esa maternidad como un acto de amor. En el capítulo «La felicidad en una lupa», se lo comunica a sor Juana en una carta:

Y por eso, querida Juana Inés, espero que en medio de esta dicha pueda tener un bijo que mezcle nuestros quereres y encarne lo mejor de cada uno. Si mi edad aun permite que sea así. (Lavín, ibid., p. 153).

Pese a que Refugio no tiene hijos, su labor de docente la redime de esta carencia y quiere a la monja mexicana como si fuera una hija; lo mismo ocurre con sor Juana; aunque enfrascada en sus libros y publicaciones (y aquí podemos relacionar el acto de gestación con el de escritura) cuida de su sobrina Isabel María dentro del convento e, incluso, la llama «hija» al recriminarle que, por permanecer a su lado, rechazó el ofrecimiento de María Luisa de irse a España con ella.

Por otro lado, María, madre de Isabel María, reproduce los esquemas que como hermana mayor vivió más de cerca en la casa materna. Sufre la marcha del padre, la depresión de la madre y es la criada Francisca la que acude en su primera menstruación:
¿Acaso se enteró [Isabel] de la sangre que le había empezado a escurrir entre las piernas y que había sido Francisca quien le dio los paños para que los colocara en las bragas, atados a la cintura para evitar que se movieran?» (Lavín, ibid., p. 53).

Aunque en aquella época eran las criadas o esclavas quienes se encargaban de cuidar a los hijos de los patrones, María ejemplifica la orfandad, otro de los temas más cotizados por las narradoras actuales.

\section{c) El erotismo como fuente de placer y de au- torrealización femenina}

El erotismo, la exploración del cuerpo femenino y la sensualidad han inundado páginas y páginas de la prosa que escriben las narradoras a partir de los años setenta. Son frecuentes las relaciones establecidas entre escritura y deseo, lenguaje y cuerpo, que sirven para enfatizar el ansia de libertad escritural y sexual de la mujer. En el caso concreto de esta novela, observamos una hipertrofia del tema, que por un lado, muestra el modo en que los personajes femeninos buscan su identidad $y$, por otro, sirve de contraste con los métodos intelectuales que la protagonista emplea con el mismo fin.

Las mayor parte de las mujeres de la novela son poderosamente sensuales e instintivas $y$, ya sea en el presente narrativo o por medio de sus recuerdos, acceden al reconocimiento de su cuerpo y al deseo sexual; así, la madre de Juana Inés, Isabel, es presentada en el capítulo «Isabel, sin hombre» absorta en sus recuerdos juveniles -la remembranza del primer amor, el esclavo Nicolás, a partir del recuerdo de su olor; por su parte, la abuela Beatriz no sólo evoca su juventud al lado de don Pedro, sino que incluso «fue [ella] quien se acercó al cuerpo recio de su marido, fue ella quien rozó sus pechos contra la espalda porque quería que le mostrara una vez más que ella era suya» (Lavín, ibíd., p. 51).

Por otro lado, la maestra Refugio recupera la relación con su cuerpo a partir de la unión con Hermilo; otro caso es el de Bernarda Linares, quien no conoce otra forma de sentirse viva si no es con las caricias de su furtivo amante; la esclava Juana de San José también se ve reconocida en el despertar de su deseo sexual; podríamos continuar ejemplificando el tema con cada uno de los personajes femeninos, pero me detendré en la relación
Sor Juana Inés de La Cruz y el barroco novohispano a través de los modelos narrativos de la ficción histórica y del boom hispánico femenino

PAOLA MADRID MOCTEZUMA 
homoerótica entre dos jóvenes monjas, Sor Andrea e Isabel María, sobrina de sor Juana. Tales prácticas eran consideradas por la moral de la época un pecado y, en el caso de la homosexualidad masculina, era castigada con la muerte por la Inquisición (Tuñón, 1987, pp. 57-60). En esta relación, bajo la perspectiva de Isabel María, lo profano da paso a lo sacro, carne y alma se unen, pues su relación es una muestra palpable de amor:

[Cuando] Sor Andrea se apretaba a su cuerpo en las bodegas y permitía que su corazón rozase el suyo entre telas, comprendía esa promesa del paraíso, ese atisbo que Jesús le mandaba. La unión de la carne y el alma. Cuando Andrea entre rezos fingía susurrarle algo al oído para introducir su lengua en el lóbulo, Isabel María sentía en el cuerpo la presencia divina, una fuerza que la arrebataba de las procaces tareas de la tierra para elevarla. (Lavín, 2009, p. 293).

Tal y como indica Ferrús (2004, p. 13), en el mismo seno de la tradición católica, lo sagrado se inscribe en lo corpóreo, como sucede en «los misterios católicos de la Encarnación, la resurrección de la carne, la Ascensión de Cristo a los cielos y la Asunción de María, junto con la reivindicación de la presencia real de Cristo en la Eucaristía y los milagros asociados al cuerpo y la sangre».

En contraposición a lo dicho, aparece la degeneración del placer sexual, en el capítulo «Las mujeres de Belén» puesto que se describen relaciones sexuales grotescas bajo la mirada de una voyeur de excepción: la pobre sor Cecilia.

Lo corporal se erige, pues, como una forma de conocimiento, de reconocimiento y también como fuente de placer. Es curioso que el único momento en que se insinúa que Juana Inés ha podido tener un contacto físico con Cristóbal, en el capítulo «el cuerpo acariciado», resulta traumático e ingresa inmediatamente al convento de las Carmelitas Descalzas. Por ello, el erotismo sirve de contrapunto con los métodos de Juana Inés para aprehender la realidad, que no son otros que la observación y la escritura.

\section{d) El valor de la palabra y el significado del silencio}

Si bien las mujeres de la novela acceden a su identidad mediante el erotismo, la palabra y la escritura son sinécdoque de la propia sor
Juana, tema más persistente si cabe que el anterior.

En la Colonia, la educación para la mujer estaba constreñida a unas cuantas nociones elementales de escritura, aritmética, religión y labores domésticas. La escritura estaba al alcance de muy pocas, pertenecientes a las clases más acomodadas, y sus veleidades intelectuales servían no tanto para su crecimiento personal como para el lucimiento del marido, que presumía de no tener a su lado a una esposa analfabeta. Es a través de la palabra privada (las cartas, diarios y autobiografías) como se empieza a resquebrajar el silenciamiento al que estaba sometida la mujer, a la vez que se entiende como una primera vía de acceso a la creación literaria.

Además, es necesaria la consideración en este orden de cosas, de que «durante los tres primeros años de la Colonia, escritura femenina es sinónimo de escritura conventual» (Ferrús, ibid., p. 21), por lo que la palabra femenina estaba sitiada y era examinada por la estructura patriarcal dominante. De ahí que se diga que la escritura de las monjas coloniales esté llena de silencios e intersticios, pues tenían que escamotear de algún modo la vigilancia de los confesores, quienes eran los que supervisaban sus escritos para después publicarlos.

En este contexto hay que entender la escritura de sor Juana, por eso es tan meritoria su aproximación a lo que en la época se conocía como «sabio barroco» (Ferrús, ibíd., p. 22); llegar hasta donde ella lo hizo con tantas adversidades ideológicas la convierten en la excepción a la regla.

Todo ello queda reflejado en la novela, vertebrada por la insistencia en una vida consagrada al estudio y la escritura. Desde el comienzo, siguiendo de cerca la Respuesta, se narra el afán de la niña Juana Inés por apresar palabras como «colorado», «torbellino», «crepúsculo», mezcladas con cantos de arrullo, palabras procedentes de África y la lengua náhuatl.

Cuando vive en la capital, en el capítulo titulado «En casa de los Mata», se erige como una verdadera Scherezada criolla -al decir de Helena Araujo- que relata historias de reinos lejanos para que su prima Isabel pueda dormir:

Isabel vio desde su cama cómo Juana Inés dejaba los libros aquellos, soplaba la vela y se volvía para 
contarle de un reino muy lejano donde las princesas se visten con velos y están encerradas en una torre porque el rey puede tener muchas esposas y todas son muy felices bañándose juntas, hablando, paseando por el jardín, cortando flores, escuchando música sobre cojines de seda, y cómo las niñas de las esposas del sultán se vuelven princesas que saben poemas y danzas y por la noche deleitan a su esposo... (Lavín, 2009, p. 87).

A la palabra oral del cuento le sucede la continua mención a la escritura, como se ha visto, en forma de cartas o como obras literarias. Sin embargo, aparecen otras formas de elocución, dominadas por la lógica patriarcal, como la confesión y la mentira.

La confesión es el espacio masculino para la palabra manipulada, la que es dicha en voz baja, silenciosa y también para el secreto. Además constituye la puerta de acceso directo a la Inquisición. Numerosos son los momentos en la novela en que los personajes femeninos temen a la confesión, sobre todo Bernarda, sor Cecilia y las monjas amantes. Para mediar entre la confesión y la penitencia surge la mentira como otro uso deformado de la palabra, ejercida por todas ellas para desasirse del yugo masculino.

La crítica sorjuanina reciente explica el silencio al que es condenada sor Juana al final de su vida, a raíz de las polémicas suscitadas por la publicación de la Carta Atenagórica, de acuerdo con lo que Josefina Ludmer ha denominado las «tretas del débil», esto es, el silencio aparente. Este concepto se ha hecho extensible a otras formas de rebelión de escritura femenina que, de manera sutil subvierten el orden patriarcal establecido. Por una parte, Ludmer considera que «el silencio constituye su espacio de resistencia ante el poder de los otros» $(1984$, p. 50) y, por otro, se ratifica como el alcance del sumo conocimiento, ejemplificado en el arrobo final del Sueño, en tanto «cumbre del entendimiento» (Ludmer, ibid., 50).

En la novela, el silencio es igualmente considerado aparente, "polisémico» (Ferrús, 2009, pp. 92-104), ya que bajo esa condena subyace una táctica de resistencia. No obstante, el desalojo de la celda, comparada con la quema de los libros de don Quijote, y la intención de los lobos de que abandone la escritura, es la queja constante de las cuatro cartas de sor Juana:
Ahora me piden que sea otra de la que soy, que me corte la lengua, que me nuble la vista, que me ampute los dedos, el corazón, que no piense, que no sienta más de lo que es menester y propio de una religiosa. De una esposa de Cristo (Lavín, 2009, p. 17).

La redención de la escritora novohispana viene propiciada por la palabra velada, el enigma. Al comienzo de esta exposición hicimos alusión al propósito de Mónica Lavín de restablecer con justicia la imagen de una escritora que jamás dejó de escribir, valiéndose de la ayuda de su amiga la marquesa de la Laguna y del contacto con las monjas portuguesas a quienes iban dirigidos Los Enigmas de la Casa del Placer.

Así queda justificado que sor Juana, al final de sus días, firmara con sangre en el arco de la enfermería del convento "Yo, la peor», la que no se calla, la que nunca se da por vencida. Se explica, de este modo, en el capítulo final "Con sangre tinta», el título de la obra, que es lo primero que se lee en su portada.

En el principio está el final.

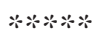

Una de las aportaciones más notables de esta novela es, a mi juicio, la posibilidad de conocer a sor Juana Inés de la Cruz y la época barroca novohispana con familiaridad y justicia histórica. A partir de su lectura, nos adentramos no sólo en la Historia sino también en el devenir de la sociedad del siglo XVII, según los «entretelones de la época» al decir de Jorge Volpi (1996, p. 73).

Queda patente que sor Juana rebosa actualidad, pues su trayectoria vital y creativa se amolda cabalmente a la las reivindicaciones de la narrativa femenina actual que, de la pluma de Mónica Lavín, traza un puente entre las dos orillas del acontecer textual: el Barroco y la Posmodernidad. Es claro que este personaje histórico ha cimentado los orígenes del feminismo en Latinoamérica $y$, particularmente, de la narrativa femenina en México. A las «hijas de la Malinche» de las que hablaba Margo Glantz hay que sumarles las «hijas de sor Juana». Así, la genealogía queda completada.

\section{Bibliografía}

Birmajer, Marcelo (2002), «La novela sin héroes: ¿acaso alguien quiere que atrapen a Ripley?», en AAVV., Desafíos de la fic-
Sor Juana Inés de La Cruz y el barroco novohispano a través de los modelos narrativos de la ficción histórica y del boom hispánico femenino

PAOLA MADRID MOCTEZUMA 
ción, Alicante, Cuadernos de América sin nombre, pp. 87-93.

Ciplijauskaité, Biruté (1988), La novela femenina contemporánea (1970-1985). Hacia una tipología de la narración en primera persona, Barcelona, Antrhopos.

Cruz sor Juana Inés de la (1978), Selección, Madrid, Editora Nacional.

Ferrús Antón, Beatriz (2004), Discursos cautivos: convento, vida, escritura, Valencia, Universitat de València.

Franco, Jean (1993), Las conspiradoras. La representación de la mujer en México, México, Fondo de Cultura Económica/El Colegio de México.

Lavín, Mónica (2009), Yo, lo peor, México, Grijalbo.

Ludmer, Josefina (1984), «Tretas del débil», en Patricia Elena González y Eliana Ortega, La sartén por el mango. Encuentro de escritoras latinoamericanas, Río Piedras, Ediciones Huracán, pp. 47-54.

Llarena, Alicia (1995), «Multiplicidad y hallazgo de un ojo posmoderno (Mujeres de ojos grandes, de Ángreles Mastretta)», en Carmen Ruiz Barrionuevo y César Real Ramos (eds.), La modernidad literaria en España e Hispanoamérica, Salamanca, Universidad de Salamanca, pp. 185-195.

Mattalía, Sonia (2003), Máscaras suele vestir. Pasión y revuelta: escritura de mujeres en
América Latina, Madrid/Frankfurt, Iberoamericana/Vervuert.

Paz, Octavio (1982), Sor Juana Inés de la Cruz o Las trampas de la fe, Barcelona, Seix Barral.

Perelmuter, Rosa (2004), Los límites de la femineidad en Sor Juana Inés de la Cruz, Madrid, Iberoamericana.

Poot Herrera, Sara (1999), «Sor Juana. Nuevos hallazgos, viejas relaciones», Anales de literatura Española. Letras novohispanas, 13, pp. 63-83.

Reisz, Susana (1990), «Hipótesis sobre el tema "escritura femenina e hispanidad" ", Tropelías. Revista de teoría de la literatura y literatura comparada, 1, pp. 199-213.

Rich, Adrienne (1996), Nacemos de mujer. La maternidad como experiencia e institución, Madrid, Cátedra.

Sabat de Rivers, Georgina (1997), «Mujeres nobles del entorno de Sor Juana», en Luis Sáinz de Medrano (ed.), Sor Juana Inés de la Cruz, Roma, Bulzoni Editore, pp. 171-191.

Tuñón Pablos, Julia (1987), Mujeres en México. Una historia olvidada, México, Planeta.

Volpi, Jorge (1996), «Cómo inventar y destruir un imperio en diecinueve lecciones», Revista de Literatura Mexicana Contemporánea, 1:2, pp. 73-76.
Sor Juana Inés de La Cruz y el barroco novohispano a través de los modelos narrativos de la ficción histórica y del boom hispánico femenino

PAOLA MADRID MOCTEZUMA 